\title{
AID AND AGENCY IN AFRICA EXPLAINING FOOD DISBURSEMENTS ACROSS ETHIOPIAN HOUSEHOLDS, 1994-2004.
}

\author{
NZINGA H. BROUSSARD \\ Email: broussard.5@osu.edu \\ The Ohio State University
}

\author{
STEFAN DERCON \\ Email: Stefan.Dercon@economics.ox.ac.uk \\ University of Oxford
}

ROHINI SOMANATHAN

Email: rohini@econdse.org

Delhi School of Economics

University of Delhi

Working Paper No. 208 


\title{
Aid and Agency in Africa
}

Explaining Food Disbursements Across Ethiopian Households, 1994-2004.

\author{
Nzinga H. Broussard* Stefan Dercon ${ }^{\dagger} \quad$ Rohini Somanathan ${ }^{\ddagger}$
}

December 30, 2011

\begin{abstract}
We study the distribution of food aid in Ethiopia between 1994 and 2004 using data from the Ethiopian Rural Household Survey. Over this period village leaders had considerable discretion in disbursing aid subject to official guidelines and periodic monitoring. We use a principal-agent model and household panel data for approximately 940 households to understand biases in the allocation of aid. The model shows that correlations between aid and observed measures of need are not a good measure of targeting because agents have incentives to distort allocations within targeted classes. Consistent with the model, we find that the aid recipients match official criteria but disbursements are negatively correlated with determinants of need that are not easily observable by monitoring agencies, namely pre-aid consumption, self-reported power and involvement in village-level organizations. Our results suggest informal structures of power within African villages influence the extent to which food aid insulates some of the world's poorest families from agricultural shocks but also that policy guidelines do constrain permissible deviations from need-based allocations.
\end{abstract}

\footnotetext{
*The Ohio State University, broussard.5@osu.edu

${ }^{\dagger}$ University of Oxford, Stefan.Dercon@economics.ox.ac.uk

${ }^{\ddagger}$ Delhi School of Economics, rohini@econdse.org
} 


\section{Introduction}

Food aid to Africa is massive and controversial. During the 1990s, Sub-Saharan Africa received a third of all food aid delivered in the world and the Ethiopian share of this was about one-fifth. ${ }^{1}$ Heated debates center around the impact of such aid. Some view it as an indispensable tool for alleviating hunger in the face of natural calamities while others claim that it builds dependency, fosters corruption and weakens the basis for efficient trade flows. A proper assessment of the role of food aid in Africa requires an understanding of how existing allocations are distributed.

The regional and temporal distribution of aid within African countries has been well-studied. Barrett (2001), Shapouri and Missiaen (1990) and Zahariadis et al. (2000) all highlight political considerations among donor countries as determining aid flows over the past several decades. Other studies emphasize the role of inertia. Jayne et al. (2002) find that the historically vulnerable regions of northern Ethiopia received aid irrespective of need. Clay et al. (1999) use cross-sectional data from a nationally representative survey of households and find aid concentrated in historically deficit areas and among female-headed and elderly households with no sytematic relationship between receipts and direct measures of household food insecurity. These studies point to important deficiencies in the ability of aid to insulate the Ethiopian economy from aggregate shocks but tell us relatively little about its distribution within villages. These intra-village allocations are the focus of this paper.

We investigate the role of agency in the allocation of aid by modeling the potential trade-off between the richer informational set possessed by village representatives and their incentives to transfer resources to favored households or those capable of providing them with reciprocal transfers. The ambiguous effect of decentralization in public services resulting from elite capture has been highlighted in various contexts. Bardhan and Mookherjee (2005) compare centralized allocations with those resulting from local electoral competition. Galasso and Ravallion (2005) study the planner's problem of maximizing transfers to the poor, with limited information on the weights that local communities attach to poor households. We focus instead on the implications of imperfect monitoring by central authorities on the behavior of local agents. Since we are interested in intra-village allocations, we take aggregate aid as exogenous to each village and model the monitoring process based on documented descriptions

\footnotetext{
${ }^{1}$ Based on statistics from the World Food Program cited in Jayne et al. (2002).
} 
of aid distribution in Ethiopia.

The official body responsible for overseeing aid disbursements in Ethiopia is the Disaster Prevention and Preparedness Commission (DPPC). On the basis of its published guidelines for aid eiligibility, it appears to be committed to serving those in need. ${ }^{2}$ Aid is allocated to districts or weredas and then transferred to peasant associations (PAs) which cover several villages and are the lowest administrative unit in Ethiopia. ${ }^{3}$ This type of community-level targeting is common in many African countries where community leaders have been historically important and information flows between villages and higher levels of government are limited (Conning and Kevane, 2002). The National Policy on Disaster Prevention issued in 1993 emphasized the importance of local participation in the implementation of all relief projects, but also stated that relief "must be addressed to the most needy at all times and no free distribution of aid be allowed to able-bodied affected population." 4

We model the aid authorities (the DPCC or non-government organizations representing donors) as observing a list of aid recipients, a limited set of their characteristics and the amounts distributed to them. They do not directly observe household need as captured by pre-aid consumption or access to risk-sharing networks. These authorities channel aid through the local administration and control allocations through a monitoring technology which allows for the detection of large deviations from optimal allocations. Since the optimal allocation of aid to a household depends on its observable characteristics, local officials distort the pattern of transfers within classes that are targeted by donor agencies and higher levels of government.

This framework is useful because it illustrates that high correlations between aid and the characteristics of needy households outlined in policy documents need not be evidence of successful targeting. In fact, this behavior is consistent with the maximization of agent utility subject to a coarse monitoring technology. Evaluating biases in aid allocations therefore requires an analysis of how aid is distributed within the demographic groups targeted for assistance. We do this using household panel data and exploiting the idea that the local

\footnotetext{
${ }^{2}$ See Jayne et al. (2002) and Clay et al. (1999) for a further discussion of district level targeting.

${ }^{3}$ Jayne et al. (2001) outline this process and emphasize that:

The critical element of this two-stage process is that while the amount of food to be allocated to each wereda is determined at federal level (using input from regional and local levels), the actual beneficiaries are designated at the local community (PA) level (p. 890).

${ }^{4}$ Quoted in Sharp (1998), p. 5.
} 
influence of a household varies little over time, while need may vary considerably from one year to another based on weather conditions and other temporal factors.

Our data come from six rounds of the Ethiopian Rural Household Survey (ERHS) conducted between 1994 and 2004. We construct a panel data set of about 940 households living in eleven peasant associations, all of which received free food aid during this period. Our estimates based on a pooled sample indicate adherence to official guidelines. Female-headed households are more likely to receive aid while households with male adults, livestock and at least one member who has completed primary education are less likely to receive aid. Consistent with other studies of food aid which use nationally representative samples, we find pre- aid consumption has no systematic influence on aid received in estimates based on our pooled sample of villages and households.

Our main empirical contribution lies in exploring whether families with local influence manage to capture a disproportionate share of village aid. We construct measures of power based on questions that were asked in two of the six survey rounds. In Round 3, households were asked about their involvement in the administration of the village peasant association and their membership in other local organizations. In Round 6, household heads reported their perceived sense of power within the village scaled on a notional nine-step ladder. ${ }^{5}$ Since we do not have repeated observations for these variables, we examine their role through interactions with household characteristics which do vary across survey rounds. We find that aid allocations are increasing in these measures of power and that it is the richer households among the empowered that receive the most. Interestingly, it is only those female-headed households with high levels of informal power that receive systematically more aid than the average household in each village.

Our final set of results controls fixed but unobservable characteristics of households using our panel structure. We examine how aid varies with pre-aid consumption and household characteristics which vary across rounds. We find that aid disbursements are increasing in household size, as one would expect, but they are also increasing in the household's pre-aid consumption, which is clearly against official guidelines. A doubling of per capita consumption leads to a 15 percent increase in the allocation of aid. We extract the household fixed-effects from this model to estimate their relationship to the measures of household

\footnotetext{
${ }^{5}$ Caeyers and Dercon (2008) use this round of data and and measures of social connections to focus on the aftermath of a specific crisis, the drought in 2002/03, during which more than 10 million people required food assistance.
} 
power described above. We find a positive relationship with self-reported power.

Overall, our results suggest that the probability of being selected as an aid recipient is negatively correlated with observable measures of wealth, in line with official guidelines, but there are also indications of aid capture by richer and locally influential households within targeted classes. We do not assess the impact of such misallocation on household welfare. There are, however, other studies using the same data that find long-term benefits of aid on at least some household members and thereby point to welfare costs associated with the failures in targeting that we document here. ${ }^{6}$

We proceed in the next section with a brief institutional history of organizations involved in the allocation of food aid in Ethiopia. Our model of agency in Section 3 is followed by a description of our in Section 4 and results in Section 5. Section 6 concludes.

\section{The administrative structure}

The Disaster Prevention and Preparedness Commission ( formerly known as the Relief and Rehabilitation Commission), was established in response to the famine of 1973/1974 in northern Ethiopia. Its mandate was to prevent disasters and reduce individual and household vulnerability to agricultural shocks. The effectiveness of food aid targeting is viewed as crucial to its success. With help from international donors and non-government organizations, the DPCC assesses weather conditions, crop production, livestock availability, wage labor opportunities, and market prices for chronically needy districts at least twice a year to capture the two agricultural seasons. ${ }^{7}$ All other districts conduct their own assessments and report estimates of need to the commission.

The DPPC periodically announces criteria for distributing aid. Groups explicitly targeted for assistance are the old, disabled, lactating and pregnant women, and those attending to young children. The original guidelines were formulated in 1979 and the National Policy on

\footnotetext{
${ }^{6}$ Gilligan and Hoddinott (2007) investigate the impact of the two different forms of emergency aid, free distribution and food-for-work, using two rounds of the same dataset. They find effects of free distribution and food for work programs on household consumption persisted 18 months after aid allocations had been made. Broussard (2011) finds that food aid in the form of free distribution improves the health, as measured by the BMI, of male adult household members but has an adverse effect on female adult household members.

${ }^{7} \mathrm{~A}$ chronically needy district is one that has required assistance for several consecutive years.
} 
Disaster Prevention and Management was passed in 1993 (TGE, 1993). The responsibility for identifying needy households has always remained with local leaders in village peasant associations who are, in turn, monitored by higher-level authorities. Monitoring occurs via random audits (Allingham and Sandmo, 1972) or through a village-level appeals system (TGE, 1993).

The sixth round of the Ethiopian Rural Household Survey, which will be described in detail in Section 4, asks household heads and members of peasant associations for criteria that they believe are used in identifying aid recipients. Table 1 lists the top five responses for each of these groups. There is considerable agreement across respondents, with the elderly, poor and disabled figuring prominently in both lists. Qualitative responses from interviews with local leaders confirm this pattern. ${ }^{8}$ It appears that deviations from the targeting principles laid out by the DPPC occur within the targeted groups. The next section presents a theoretical justification for this pattern, showing that it can be derived from the behavior of rational agents responding to a monitoring technology which approximates what is observed in Ethiopia.

\section{A model of aid allocation}

We model the problem of aid allocation as one in which a principal (the DPPC or a donor organization) channels aid through an agent (the peasant association) and has some imperfect monitoring technology that influences agent payoffs. ${ }^{9}$ The principal's objective is to maximize village welfare. The agent, while attaching some weight to this objective, may also direct aid to families with local influence or with the capacity to provide reciprocal favors. We assume that the aggregate aid allocation to a village is exogenous. ${ }^{10}$

\footnotetext{
${ }^{8}$ Kay Sharp interviewed a large number of local elders on targeting criteria, and quotes from an interview with a wereda chairman in the Hawzien area:

If the quota is enough someone with five goats may be included, but if the quota is small someone with only one hen may be excluded in favor of someone with nothing (Sharp, 1998, p. 17).

${ }^{9}$ We frame the problem in terms of a single agent and thereby avoid questions of collective action within the peasant association.

${ }^{10}$ Aid authorities may want to provide more aid to villages that disburse it effectively, although there is little evidence of this. Since our focus is on intra-village allocation and our sample contains multiple years but only a limited number of peasant associations, we do not explore the feedback effect on aggregate aid
} 
The optimal allocation of aid depends on the social welfare function of the principal. If the welfare of each household is an increasing, concave function of household consumption $(c)$, a utilitarian planner would provide each household aid $(a)$, in proportion to the shortfall of its pre-aid consumption from a given threshold. This threshold $\bar{c}_{j}$ would be jointly determined by the total aid allocated to the village $\left(A_{j}\right)$, and the pre-aid distribution of consumption. If total aid is lower, then the planner would reduce $\bar{c}_{j}$ rather than spread aid more thinly.

To elaborate, if the distribution function for pre-aid consumption is $G_{j}(c)$, the post-aid consumption distribution $G_{j}^{*}(c+a)$ is:

$$
G_{j}^{*}(c+a)=\left\{\begin{array}{rc}
0 & c+a<\bar{c}_{j}, \\
G_{j}\left(\bar{c}_{j}\right) & c+a=\bar{c}_{j}, \\
G_{j}(c) & c+a>\bar{c}_{j}
\end{array}\right.
$$

The optimal post-aid distribution of consumption is thus identical to the pre-aid distribution above $\bar{c}_{j}$. All those initially below $\bar{c}_{j}$ receive aid just enough for them to form a mass at $\bar{c}_{j}$. This allocation would also minimize the poverty gap ratio and all poverty measures that satisfy the Pigou-Dalton principle. It is therefore also optimal under all welfare functions that are decreasing in these measures.

The principal knows the distribution of pre-aid consumption and can therefore determine $\bar{c}_{j}$ but does not observe consumption for particular households. For each household $i$ within a sampled set, the principal observes the allocation of aid $a_{i}$ and a set of characteristics $\mathbf{x}_{i}$. Based on the perceived correlation of these characteristics with consumption, the principal assigns them weights $\beta$. We denote the remaining unobserved components of consumption by $\epsilon$. The consumption of household $i$ can therefore be written as

$$
c_{i}=\mathbf{x}_{i} \beta+\epsilon_{i}
$$

received by a village. 
If $\epsilon_{i}$ was known, the principal could of course simply direct the agent to allocate $a_{i}=\bar{c}_{j}-c_{i}$ to all households below $\bar{c}_{j}$ and nothing to those above this threshold. This type of information is however rarely available to authorities, hence the decentralization dilemma of how to use local knowledge while trying to implement social objectives.

Suppose that the unobservable component of need, $\epsilon$, takes values in $(-\bar{\epsilon},+\bar{\epsilon})$. The minimum and maximum levels of aid to a household $i$ in village $j$ consistent with the planner's solution are given by $\underline{a}_{i j}$ and $\bar{a}_{i j}$ respectively where

$$
\begin{aligned}
& \underline{a}_{i j}=\bar{c}_{j}-\mathbf{x}_{i j} \beta-\bar{\epsilon} \\
& \bar{a}_{i j}=\bar{c}_{j}-\mathbf{x}_{i j} \beta+\bar{\epsilon}
\end{aligned}
$$

If the principal can punish the agent enough to ensure compliance and only punishes when he is certain of misallocation, aid transfers will always lie within this interval. Notice that the length of the interval is decreasing in $\mathbf{x} \beta$. In particular, if $\mathbf{x}_{i j} \beta-\bar{\epsilon}>\bar{c}_{j}$, the household can never receive aid and if $\mathbf{x}_{i j} \beta+\bar{\epsilon}$ is close to zero, the household receives the maximum possible aid, $a_{i j}=\bar{c}_{j}$. For intermediate values of $\mathbf{x} \beta$, the transfer received by the household will depend on agent preferences. If, for instance, agents prefer households with characteristics $Z$ and $\gamma$ represents the weights attached by the agent to these characteristics, households with the high values of $Z \gamma$ will receive the most aid, subject to the constraint that transfers are less than $\bar{a}_{i j}(\mathbf{x} \beta)$. In the special case where $Z$ is statistically independent of $X$, the largest allocations would be to households with the lowest values of $\mathbf{x} \beta$. To identify the elements of $Z$ and the weights $\gamma$ attached to them, we have to look within targeted classes, as measured by the value of $\mathbf{x} \beta$ for each household. This is the basis of our empirical strategy. ${ }^{11}$

The above model tells us that when the preferences of the agent and the principal diverge, the agent has the greatest flexibility in assigning aid to households that lie within the set that the principal considers needy. In such cases, it would be inappropriate to interpret the correlation between officially accepted characteristics of need as an indication of targeting. One needs to look at those characteristics of households that are likely to bias agent allocations and are unobservable to the principal, yet measured in the survey data.

\footnotetext{
${ }^{11}$ This very stylized model could be generalized in a number of ways. The domain of $\epsilon$ could be unbounded and the principal could punish for a high enough probability of misallocation rather than only when misallocation is certain. These more complicated scenarios add little to the main insight here, which is that agents would want to allocate to favored households within officially targeted classes.
} 


\section{Data}

We use data from six rounds of the Ethiopain Rural Household Survey (ERHS), a longitudinal household survey conducted in 15 peasant associations across rural Ethiopia between 1994 and 2004. ${ }^{12}$ Each peasant association consists of a handful of villages. Our analysis is restricted to the 11 associations that received food aid at some point during this period. A standard problem in longitudinal data analysis is attrition. The ERHS has the advantage of very limited attrition of about $3 \%$ per round. ${ }^{13}$

Aid in Ethiopia is received either through food for work programs or as free distribution. Villages typically have only one of these programs in place and for our sample, it is the latter. Our measure of aid consists of all gifts from the government or non-government organizations received by the household in the form of food aid or donations. The survey records these transfers at individual level and we aggregate these for each household because most of our variables capturing need are at the household level. Official criteria for prioritizing recipients are also defined in terms of the characteristics of the household head. ${ }^{14}$ A large fraction of all aid is received in the form of wheat, maize, sorghum and cooking oil. These transfers were converted to cash equivalents using local village prices that were recorded as part of the survey.

Poverty and malnutrition rates in Ethiopia are among the highest in the world, with about half the population living in poverty based on the international dollar-a-day line. Official estimates show poverty head counts coming down slowly over our study period from $44 \%$ in 1995 to $39 \%$ in 2004 (MOFED, 2008). There are no official poverty lines for the surveyed villages (they only exist for larger regions), but using procedures similar to those used to calculate national poverty, we find poverty rates in our sample mirror national trends. Poverty in these villages based on pre-aid consumption was approximately $49 \%$ in 1994 , and went down to $34 \%$ in $2004 .{ }^{15}$ An important caveat here is that pre-aid consumption may not be an accurate counterfactual for household consumption in the absence of aid because

\footnotetext{
${ }^{12}$ The first three rounds were collected over the two years 1994 and 1995. Rounds 4, 5 and 6 were in 1997, 1999 and 2004 respectively. A seventh round of data, collected in 2009, is not yet in the public domain.

${ }^{13}$ Previous studies using these data (Caeyers and Dercon, 2008) found that patterns of attrition were similar across aid-recipients and non-recipients.

${ }^{14}$ Qualitative studies on the distribution of aid also suggest that it is the head that is eligible to receive aid and other household members can be designated to pick up the aid when the head is unable to do so (Sharp, 1997).

${ }^{15}$ Details on methods and estimates are in Dercon et al. (2009).
} 
it ignores the behavioral responses to aid. If aid had not materialized, households may have sold assets or migrated in search of food. We think of these rates as merely indicative of conditions in the surveyed villages over this period.

Need is by no means identical across time and space. Table 2 shows poverty rates, averaged across rounds, for each of the 15 peasant associations surveyed together with the fractions of poor and non-poor households receiving aid. Table 3 displays round-wise averages. We observe considerable variation in poverty rates across villages and survey rounds. For a single village, poverty rates can more than double between rounds and aid flows rarely match these changes. The tables also show poverty gaps and their coverage through aid. In most villages and most rounds aid covers only a fraction of the poverty gap. ${ }^{16}$ In our pooled sample we find the shares of poor and non-poor receiving aid are very similar. This low correlation between consumption and food aid is consistent with other studies (Jayne et al., 2002; Clay et al., 1999; Dercon and Krishnan, 2003).

These summary measures confirm the deficiencies in targeting discussed in previous work but tell us relatively little about the systematic biases in intra-village aid allocations that are the focus of our study. Nor do they offer us evidence in favor of the particular model of agency proposed in Section 3. To test the model, we incorporate characteristics of households that are likely to affect agent behavior but are of little direct interest to the principal. We rely on two indicators of the influence households may enjoy in the village community. In round 3, households were asked whether they held positions in formal and informal village organizations. Some of these positions are elected, others, including those to the PA, are appointed and associated with considerable prestige within the village. As seen in Table 4, about one-third of our household heads in our sample held some type of position and $15 \%$ were members of the PA committee.

Our second measure of influence is based on responses to the following question, asked of household heads in round 6 :

Please imagine a nine-step ladder, where on the bottom, the first step, stand people who are completely without rights, and step 9, the highest step, stand those who have a lot of power. On which step are you?

\footnotetext{
${ }^{16}$ The tables do not show average poverty rates for each village by round in the interest of parsimony.
} 
We create an indicator variable for power which equals one if the household head reports to be on step six or higher. About one-third of the sample is empowered by this measure.

In the subsequent analysis we refer to these two measures of local influence as Office and Power respectively. Their sample means are almost the same but they are only weakly correlated, with a correlation coefficient of only 0.04. Based on estimates from a simple linear probability model shown in Table 5, both measures are positively correlated with education. Households with some primary education show a 7 percentage point increase in each of these measures. Female-headed households report lower values ( 8 and 15 percentage points for Power and Office respectively). Larger households and those with more livestock are more likely to hold office, though their perceptions of empowerment do not seem to vary systematically.

It is worth pointing out that these measures of local influence do not simply proxy for the economic standing of the household. In round 3 of the survey households were asked to identify the most powerful individuals in the village and then explicitly asked about the source of such power. The number one response was personal organizational ability, the second was being an elder. The other three sources referred to were personal charisma, political connections, membership of the PA committee. This suggests that allocating aid to those with local influence may be consistent with serving officially targeting categories, although it would clearly suggest a divergence between the preferences of the principal and the agent.

Table 6 describes the variables used in our analysis and Table 7 compares their values for aid recipients and non-recipients. We observe no systematic difference in consumption levels across the two groups but find that observable characteristics of households appears to be in line with official guidelines; those receiving aid have lower education, are more likely to be female-headed, have fewer adults in their household and have less livestock. They do have somewhat more land, but it is hard to interpret this because of big differences in land quality between villages. Some of the villages that are more likely to receive aid such as Doma or Korodegaga have larger holdings but lower quality land. There is no correlation between any of the power variables and receiving aid. We now turn to a more careful identification of the empirical distribution of aid within villages and explore importance of local influence relative to the need-based characteristics. 


\section{$5 \quad$ Empirical strategy and results}

We consider two outcomes at the household level; the probability of receiving aid and the cash-equivalent of aid received. Each of these is a function of household characteristics that are observable to the aid authorities and those that are observed only by those within the village. For household $i$ in village $j$ at time $t$ we specify:

$$
Y_{i j t}=f\left(X_{i j t}, Z_{i j t}, v_{j t}, h_{i}\right)
$$

$X_{i j t}$ denotes easily identifiable household characteristics (household assets and demographics), $Z_{i j t}$ are only observed within the village and and in our survey data (membership of informal village groups, household consumption), $v_{j t}$ are unobservable time-varying village effects and $h_{i}$ is a household fixed-effect which may include its ability to use risk-sharing networks in times of need.

For assests, we use the the value of all livestock and per capita land holdings in $1994 .{ }^{17}$ As most agriculture is rain-fed, agricultural incomes vary with rainfall and we therefore include the interaction of land and rainfall from the previous season as an explanatory variable. For demographics we use household size, the age and gender of the household head, an indicator for any member having completed primary education and the total number of male and female adults to capture dependency ratios and vulnerability. Our primary measure of need is per capita consumption minus aid receipts. This is unlikely to be observable to aid authorities and therefore enters $Z$, along with measures of local influence.

On average about $16 \%$ of households in a peasant association receive aid (Table 2). Table 8 presents results on the probability of receiving aid using a standard probit model and a pooled sample of villages and rounds that received some aid. The estimates in Columns (1) and (2) show that, in line with DPCC guidelines, households with more male adults, education and livestock are less likely to receive aid. Having some primary education decreases the probability of getting food aid by about $6 \%$ and being female-headed increases it by about $7 \%$. The coefficient on consumption is negative but insignificant, in line with other studies

\footnotetext{
${ }^{17}$ Ethiopia has a restricted land market, all land is owned by the Ethiopian government with longterm usufruct rights. Land is restricted from being sold or leased. Detailed information on landholdings was collected in the 1994 survey and we use the measure of land suitable for cultivation in that year.
} 
(Clay et al., 1999). ${ }^{18}$

Controlling for wealth and other characteristics of need, holding an official position in the village increases the probability of receiving aid by $5 \%$ or about a third of mean probability of getting aid. This result is similar to the findings in Caeyers and Dercon (2008) for the specific crisis in 2002 but now averaged over a much longer period. Notice that a doubling of livestock holdings reduces this probability by $1.6 \%$, so only considerably less livestock compensates for this effect. Holding such a position could influence aid through a variety of channels. Those in strategic positions may, for example, have an informational advantage in that they know when aid comes in and how to best claim it. Or it may result from capture, allowing them to jump the queue, past more deserving households.

Our model in Section 3 predicts distortions within officially targeted classes. We test this through the specification in Column (3) of Table 8 by interacting some of our explanatory variables with our measures of influence, namely self-reported power and holding a position in a village organization. For continuous variables such as livestock and consumption, interactions are with the demeaned values. We find that for both our measures of power, it is the richer households that are more likely to receive aid, clearly against official guidelines. Households with fewer male adults are still less likely to receive aid, but none of the other demographic variables remain statistically significant.

These biases in allocation are even more pronounced when we examine the levels of aid disbursed. Since a large number of households do not receive any aid, we estimate a Tobit model with the log of monthly aid receipts as our dependent variable. Estimates are presented in Table 9. For both our measures, Office and Power, it is households with high levels of preaid consumption within these groups that receive the most aid. For those holding local office, a one standard deviation increase in the log of pre-aid consumption is associated with an $15 \%$ increase in the value of aid received. For those with self-reported power, the corresponding effect is $11 \%$. Interestingly, it is only those female-headed households reporting high levels of informal power that receive systematically more aid.

To summarize, these results suggest that local influence allows households within targeted groups, such as female-headed households, to gain access to more aid but it may also lead to

\footnotetext{
${ }^{18}$ In their study they use income instead of consumption and attribute the absence of a correlation between aid and income to a disproportionate number of female and elderly headed households receiving aid regardless of need.
} 
misallocation away from those most in need. Recall that about a third of households report holding some official position and if we include our measure of self-reported power, over half the households in the sample are empowered in some way. This is a high percentage and allows for aid to be allocated to those with influence within categories that makes them appear needy to higher-level authorities. It may also mean considerable deprivation for that half of the population that does not have access to these sources of patronage.

Our final set of results exploit the panel structure of our data to ask whether households received more aid in years in which their need was greater. Table 10 presents least squares coefficients of our explanatory variables on the size of the food transfer allowing for household fixed effects. We include all households who get food aid during any part of our survey period. Larger households receive $9 \%$ more per additional household member. Coefficients on education and female-headedness all indicate targeting according to guidelines, though none of these precisely estimated. This is not surprising given the limited variation in these variables within households over time. Changes in household heads, for example, typically arise through the death or migration of the head. The most striking result is the positive and statistically significant relationship between pre-aid consumption and aid transfers. On average, households appear to capture more in years that they seem to need less.

Since our measures of power do not vary by round, we cannot include them in the above model. We can, however, extract estimated household fixed effects from this procedure and explore their relationship with local power. We do this in Table 11 using a linear model in which the estimated household fixed effects are the dependent variable and our measures of local influence and other household characteristics are explanatory variables. ${ }^{19}$ We find both power variables are positive with self-reported empowerment statistically significant.

A potential criticism to our analysis is that the observed positive correlation between power and aid allocations may reflect reverse causality. It may be that receiving food aid creates a sense of empowerment. This is unlikely to be the full story. As we see in Table 5, power is correlated with household characteristics such as wealth, gender and education that are generally associated with status and earning capacity. Moreover, only about half of those reporting local power get aid. We have also found that within this group, it is those with high pre-aid consumption that receive the biggest transfers.

\footnotetext{
${ }^{19}$ The specification in Column(1) includes only per capita land holdings as an additional explanatory variable while that in Column (2) also includes the means of all the other the explanatory variables in Table 10 .
} 


\section{Conclusion}

The effectiveness of public assistance programs depends on how well they identify vulnerable households. This is especially true in poor, rural economies such as Ethiopia that are subject to periodic agricultural crises and inadequate domestic food availability. Aid forms a critical source of food supply at these times and its effective distribution can avert large-scale starvation. International donor agencies have limited information about local conditions and do not control distribution networks. They necessarily rely on national governments to set policies and on village leaders to identify those in need. This paper examines the distribution of aid within villages and provides a theoretical framework and evidence that can help understand the nature of targeting biases.

We find that households with local influence are more likely to receive aid and receive larger amounts of aid than warranted by objective measures of need. We also find however, that biases in allocation occur within the groups that are targeted in official policy documents. This finding is important because it suggests that aid distribution is constrained by policy and that local leaders do appear to be monitored by higher-level agencies. The distribution of aid at the local level is neither completely at the discretion of village leaders, nor does there seem to be a tendency to distribute it equally across villagers, as has been suggested previously (Sharp, 1997). Awareness of such agency is important because it implies that better designed policies can lead to improved targeting, albeit with some local manipulation. 
Table 1: Top Five Criteria for the Allocation of Aid

\section{Village Members}

1 Old people [50.38]

2 Disabled [45.22]

3 People who seem to be poor [42.19]

4 Drought [19.27]

5 Quota for the village [17.60]

\section{Village Representatives}

1 Poor people

2 Old people

3 Large households

4 Disabled

5 Households with no support

Notes: In round 6 household heads were asked "How was free food allocated in this community?" Village representatives were asked "What are the criteria by which free food is allocated to members of this PA?" 1214 households responded to the question, 659 households from the villages used in our analysis. The percentage of our sample listing each criterion as one of their top four appear in brackets. Apart from the listed options, $13.2 \%$ and $8.19 \%$ of the sampled households reported land and cattle as important criteria. 


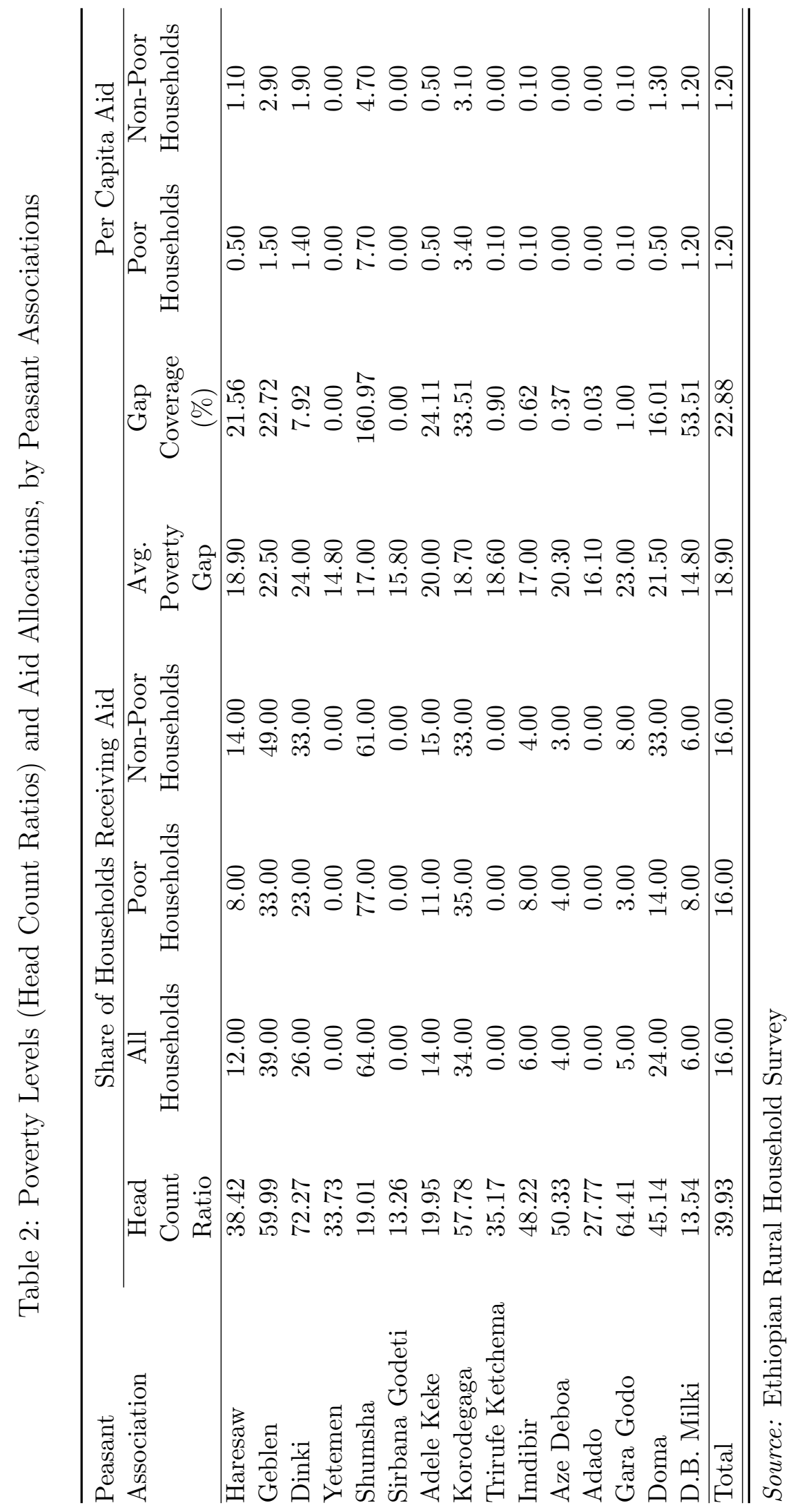




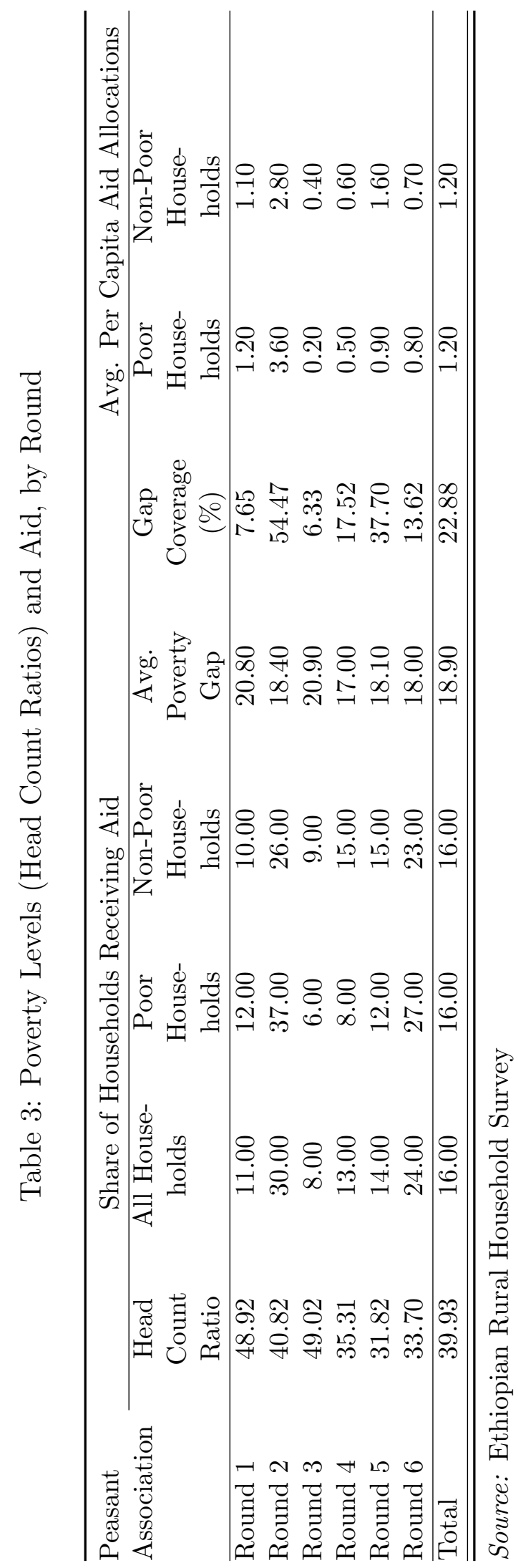


Table 4: Ever Held Formal/Informal Office?

\begin{tabular}{lcc}
\hline Type of Position & ERHS $(\%)$ & Sample $(\%)$ \\
\hline No office & 64.16 & 66.88 \\
High office & 7.32 & 6.48 \\
PA Chairman & & \\
PA Treasurer & & \\
PA Secretary & 17.34 & 15.18 \\
PA committee member & 11.18 & 11.46 \\
Other office & & \\
Women's association & & \\
Youth association & \\
Iddir (mutual insurance group) & & \\
Equb (credit society) & & \\
Religious office & & \\
\end{tabular}

Notes: In round 3, household heads were asked if they "ever held a formal or informal office". If yes, the respondent was asked to list all former positions. We use the highest ranking position. 
Table 5: Correlates of Power

\begin{tabular}{|c|c|c|}
\hline & Power & Office \\
\hline Log consumption per capita & $\begin{array}{c}0.023 \\
(0.036)\end{array}$ & $\begin{array}{c}0.098^{* * *} \\
(0.028)\end{array}$ \\
\hline Primary education & $\begin{array}{c}0.067^{* *} \\
(0.034)\end{array}$ & $\begin{array}{c}0.067^{* *} \\
(0.029)\end{array}$ \\
\hline Female head & $\begin{array}{c}-0.079^{* *} \\
(0.038)\end{array}$ & $\begin{array}{c}-0.145^{* * *} \\
(0.032)\end{array}$ \\
\hline Age & $\begin{array}{l}-0.001 \\
(0.001)\end{array}$ & $\begin{array}{c}0.001 \\
(0.001)\end{array}$ \\
\hline Household size & $\begin{array}{l}-0.012 \\
(0.010)\end{array}$ & $\begin{array}{c}0.027^{* * *} \\
(0.008)\end{array}$ \\
\hline Male adults & $\begin{array}{c}0.017 \\
(0.021)\end{array}$ & $\begin{array}{l}-0.003 \\
(0.018)\end{array}$ \\
\hline Female adults & $\begin{array}{c}0.019 \\
(0.023)\end{array}$ & $\begin{array}{c}0.017 \\
(0.019)\end{array}$ \\
\hline Log livestock value & $\begin{array}{c}0.005 \\
(0.010)\end{array}$ & $\begin{array}{c}0.016^{* *} \\
(0.008)\end{array}$ \\
\hline Log land & $\begin{array}{l}-0.073 \\
(0.098)\end{array}$ & $\begin{array}{c}0.107 \\
(0.082)\end{array}$ \\
\hline Village fixed effects & Yes & Yes \\
\hline Obs. & 1247 & 1480 \\
\hline R-squared & 0.09 & 0.22 \\
\hline
\end{tabular}

Significance levels : $\quad * 10 \% \quad * * 5 \% \quad * * * 1 \%$

Notes: The sample includes all households in the 15 sampled villages of the ERHS.

Explanatory variables are averaged over the 6 rounds. 
Table 6: List of Variables

Aid The sum of all gifts from the government or non-government organizations received by any household member, aggregated at village prices.

Log consumption per capita (cons) Household consumption from own production, purchased meals and non-food expenditures (excludes public and private transfers).

Log livestock value (livestock) Households value of livestock holdings.

Log land Per capita cultivated land holdings in 1994

Log land*rain Log land interacted with village rainfall from the previous season.

Power Indicator that equals 1 if the head of household gives a power ranking of 6 or higher on the following question: "Please imagine a nine-step ladder, where on the bottom, the first step, stand people who are completely without rights, and step 9, the highest step, stand those who have a lot of power. On which step are you?"

Office Indicator that equals 1 if household head or spouse participated in a village organization (see Table 4)

Primary education (edu) Indicator that equals 1 if current member of household completed either religious, primary, secondary, or university education.

Female head (femalehd) Indicator equals 1 if head of the household is female.

Age Age of the household head.

Agesq Square of the age of the household head.

Household size Number of household members

Male adults Number of male adults aged 15-55.

Female adults Number of female adults aged 15-55.

The abbreviated versions of variables are in parentheses and used in some of our tables. 
Table 7: Summary Statistics

\begin{tabular}{|c|c|c|c|c|}
\hline \multirow[b]{2}{*}{ Variable } & \multicolumn{2}{|c|}{ Means } & \multirow[b]{2}{*}{ Diff } & \multirow[b]{2}{*}{ t-stat } \\
\hline & No Aid & Aid & & \\
\hline Log consumption per capita & 4.178 & 4.216 & -0.037 & -1.03 \\
\hline Primary education & 0.438 & 0.357 & 0.081 & 4.02 \\
\hline Female head & 0.292 & 0.348 & -0.056 & -2.90 \\
\hline Power & 0.352 & 0.361 & -0.009 & -0.44 \\
\hline Office & 0.330 & 0.327 & 0.003 & 0.16 \\
\hline Age & 48.944 & 48.799 & 0.146 & 0.24 \\
\hline Household size & 5.824 & 5.223 & 0.601 & 5.73 \\
\hline Male adults & 1.336 & 1.129 & 0.207 & 5.05 \\
\hline Female adults & 1.479 & 1.280 & 0.199 & 5.24 \\
\hline Log livestock value & 5.071 & 4.581 & 0.490 & 5.75 \\
\hline \multirow[t]{2}{*}{ Log land } & 0.195 & 0.220 & -0.026 & -3.01 \\
\hline & 1168 & 1173 & & \\
\hline
\end{tabular}

Notes: Includes villages only in rounds in which they received aid. 
Table 8: The Probability of Receiving Aid, Marginal Effects (Probit).

\begin{tabular}{|c|c|c|c|}
\hline & Dependent Variable: & Binary variable & Aid $=1$ if any aid received \\
\hline \multirow{3}{*}{ Log consumption per capita } & $(1)$ & $(2)$ & $(3)$ \\
\hline & -0.011 & -0.005 & -0.037 \\
\hline & $(0.018)$ & $(0.018)$ & $(0.023)$ \\
\hline \multirow[t]{2}{*}{ Log livestock value } & & $-0.015^{* *}$ & -0.011 \\
\hline & & $(0.006)$ & $(0.007)$ \\
\hline \multirow[t]{2}{*}{ Power (d) } & 0.019 & 0.020 & 0.019 \\
\hline & $(0.026)$ & $(0.026)$ & $(0.038)$ \\
\hline \multirow[t]{2}{*}{ Office (d) } & $0.049^{*}$ & $0.051^{*}$ & 0.065 \\
\hline & $(0.028)$ & $(0.029)$ & $(0.042)$ \\
\hline \multirow[t]{2}{*}{ Power*cons } & & & $0.058^{*}$ \\
\hline & & & $(0.034)$ \\
\hline \multirow[t]{2}{*}{ Power*edu (d) } & & & -0.058 \\
\hline & & & $(0.054)$ \\
\hline \multirow[t]{2}{*}{ Power*livestock } & & & -0.024 \\
\hline & & & $(0.015)$ \\
\hline \multirow[t]{2}{*}{ Power*femalehd $(\mathrm{d})$} & & & 0.074 \\
\hline & & & $(0.058)$ \\
\hline \multirow{2}{*}{ Office*cons } & & & $0.085^{* *}$ \\
\hline & & & $(0.037)$ \\
\hline \multirow[t]{2}{*}{ Office*edu (d) } & & & -0.031 \\
\hline & & & $(0.055)$ \\
\hline \multirow[t]{2}{*}{ Office*livestock } & & & 0.006 \\
\hline & & & $(0.017)$ \\
\hline \multirow[t]{2}{*}{ Office*femalehd (d) } & & & -0.044 \\
\hline & & & $(0.064)$ \\
\hline \multirow[t]{2}{*}{ Log land } & & -0.252 & -0.135 \\
\hline & & $(0.421)$ & $(0.418)$ \\
\hline \multirow[t]{2}{*}{ Log land*rain } & & 0.286 & 0.171 \\
\hline & & $(0.437)$ & $(0.433)$ \\
\hline \multirow[t]{2}{*}{ Primary education (d) } & $-0.058^{* *}$ & $-0.057 * *$ & -0.024 \\
\hline & $(0.028)$ & $(0.028)$ & $(0.040)$ \\
\hline \multirow[t]{2}{*}{ Female head (d) } & $0.083^{* * *}$ & $0.074^{* *}$ & 0.063 \\
\hline & $(0.030)$ & $(0.030)$ & $(0.039)$ \\
\hline \multirow[t]{2}{*}{ Age } & 0.004 & 0.004 & 0.004 \\
\hline & $(0.005)$ & $(0.005)$ & $(0.005)$ \\
\hline \multirow[t]{2}{*}{ Agesq } & -0.000 & -0.000 & -0.000 \\
\hline & $(0.000)$ & $(0.000)$ & $(0.000)$ \\
\hline \multirow[t]{2}{*}{ Household size } & 0.001 & 0.003 & 0.002 \\
\hline & $(0.008)$ & $(0.008)$ & $(0.008)$ \\
\hline \multirow[t]{2}{*}{ Male adults } & $-0.028^{*}$ & $-0.027^{*}$ & $-0.028^{*}$ \\
\hline & $(0.016)$ & $(0.016)$ & $(0.016)$ \\
\hline \multirow[t]{2}{*}{ Female adults } & -0.015 & -0.015 & -0.014 \\
\hline & $(0.017)$ & $(0.017)$ & $(0.017)$ \\
\hline Time-varying village effects & Yes & Yes & Yes \\
\hline Log Likelihood & -1213.73 & -1210.75 & -1202.96 \\
\hline Obs. & 2341 & 2341 & 2341 \\
\hline
\end{tabular}


Table 9: Aid Disbursements, Marginal Effects (Tobit)

\begin{tabular}{|c|c|c|c|}
\hline & Depe & e: $\log M$ & ceipts \\
\hline \multirow{3}{*}{ Log consumption per capita } & (1) & (2) & $(3)$ \\
\hline & -0.012 & -0.001 & -0.060 \\
\hline & $(0.031)$ & $(0.032)$ & $(0.040)$ \\
\hline \multirow{2}{*}{ Log livestock value } & & $-0.022^{* *}$ & -0.016 \\
\hline & & $(0.011)$ & $(0.012)$ \\
\hline \multirow[t]{2}{*}{ Power (d) } & 0.018 & 0.018 & -0.012 \\
\hline & $(0.048)$ & $(0.048)$ & $(0.069)$ \\
\hline \multirow[t]{2}{*}{ Office (d) } & 0.073 & 0.074 & 0.106 \\
\hline & $(0.055)$ & $(0.055)$ & $(0.077)$ \\
\hline \multirow[t]{2}{*}{ Power*cons } & & & $0.106^{*}$ \\
\hline & & & $(0.061)$ \\
\hline \multirow[t]{2}{*}{ Power*edu (d) } & & & -0.097 \\
\hline & & & $(0.094)$ \\
\hline \multirow[t]{2}{*}{ Power*livestock } & & & -0.034 \\
\hline & & & $(0.025)$ \\
\hline \multirow[t]{2}{*}{ Power*femalehd $(\mathrm{d})$} & & & $0.207^{*}$ \\
\hline & & & $(0.115)$ \\
\hline \multirow[t]{2}{*}{ Office*cons } & & & $0.154^{* *}$ \\
\hline & & & $(0.070)$ \\
\hline \multirow[t]{2}{*}{ Office*edu (d) } & & & -0.076 \\
\hline & & & $(0.097)$ \\
\hline \multirow[t]{2}{*}{ Office*livestock } & & & 0.016 \\
\hline & & & $(0.031)$ \\
\hline \multirow[t]{2}{*}{ Office ${ }^{*}$ femalehd (d) } & & & -0.049 \\
\hline & & & $(0.113)$ \\
\hline \multirow[t]{2}{*}{ Log land } & & -0.459 & -0.251 \\
\hline & & $(0.719)$ & $(0.716)$ \\
\hline \multirow[t]{2}{*}{ Log land*rain } & & 0.495 & 0.295 \\
\hline & & $(0.756)$ & $(0.750)$ \\
\hline \multirow[t]{2}{*}{ Primary education (d) } & -0.076 & -0.077 & -0.007 \\
\hline & $(0.050)$ & $(0.050)$ & $(0.073)$ \\
\hline \multirow[t]{2}{*}{ Female head (d) } & $0.127^{* *}$ & $0.111^{*}$ & 0.061 \\
\hline & $(0.056)$ & $(0.059)$ & $(0.074)$ \\
\hline \multirow[t]{2}{*}{ Age } & 0.011 & 0.011 & 0.010 \\
\hline & $(0.008)$ & $(0.008)$ & $(0.008)$ \\
\hline \multirow[t]{2}{*}{ Agesq } & -0.000 & -0.000 & -0.000 \\
\hline & $(0.000)$ & $(0.000)$ & $(0.000)$ \\
\hline \multirow[t]{2}{*}{ Household size } & 0.015 & 0.018 & 0.017 \\
\hline & $(0.014)$ & $(0.015)$ & $(0.015)$ \\
\hline \multirow[t]{2}{*}{ Male adults } & $-0.055^{*}$ & $-0.053^{*}$ & $-0.053^{*}$ \\
\hline & $(0.030)$ & $(0.030)$ & $(0.030)$ \\
\hline \multirow[t]{2}{*}{ Female adults } & -0.042 & -0.042 & -0.038 \\
\hline & $(0.033)$ & $(0.033)$ & $(0.033)$ \\
\hline Time-varying village effects & Yes & Yes & Yes \\
\hline Obs. & 2341 & 2341 & 2341 \\
\hline Uncensored & 1173 & 1173 & 1173 \\
\hline Censored & 1168 & 1168 & 1168 \\
\hline
\end{tabular}


Table 10: Determinants of Food Aid Allocations, Household Fixed Effects

\begin{tabular}{|c|c|c|}
\hline \multicolumn{3}{|c|}{ Dependent Variable: Log Monthly Aid Receipts } \\
\hline & (1) & $(2)$ \\
\hline Log consumption per capita & $0.150^{* *}$ & $0.145^{* *}$ \\
\hline & $(0.060)$ & $(0.060)$ \\
\hline Log livestock value & & $\begin{array}{c}0.006 \\
(0.024)\end{array}$ \\
\hline Log land*rain & & $\begin{array}{c}0.468 \\
(0.639)\end{array}$ \\
\hline Primary education & $\begin{array}{c}-0.073 \\
(0.143)\end{array}$ & $\begin{array}{l}-0.070 \\
(0.143)\end{array}$ \\
\hline Female head & $\begin{array}{c}0.205 \\
(0.226)\end{array}$ & $\begin{array}{c}0.210 \\
(0.228)\end{array}$ \\
\hline Age & $\begin{array}{c}-0.053^{* *} \\
(0.024)\end{array}$ & $\begin{array}{c}-0.053^{* *} \\
(0.023)\end{array}$ \\
\hline Agesq & $\begin{array}{c}0.001^{* * *} \\
(0.000)\end{array}$ & $\begin{array}{c}0.001^{* * * *} \\
(0.000)\end{array}$ \\
\hline Household size & $\begin{array}{c}0.077^{* *} \\
(0.037)\end{array}$ & $\begin{array}{c}0.094^{* *} \\
(0.046)\end{array}$ \\
\hline Male adults & $\begin{array}{l}-0.055 \\
(0.066)\end{array}$ & $\begin{array}{l}-0.057 \\
(0.066)\end{array}$ \\
\hline Female adults & $\begin{array}{l}-0.014 \\
(0.069)\end{array}$ & $\begin{array}{l}-0.013 \\
(0.069)\end{array}$ \\
\hline Time-varying village effects & Yes & Yes \\
\hline Obs. & 1779 & 1779 \\
\hline Num. of Groups & 505 & 505 \\
\hline R-Squared Within & 0.54 & 0.54 \\
\hline
\end{tabular}

Table 11: Aid and Local Power

\begin{tabular}{lcr}
\hline \multicolumn{2}{c}{ Dependent Variable: Household Fixed Effects } \\
\hline \multicolumn{1}{c}{$(\mathbf{1})$} & $\mathbf{( 2 )}$ \\
\hline Power & $0.095^{* *}$ & $0.101^{* *}$ \\
& $(0.028)$ & $(0.041)$ \\
Office & 0.039 & 0.062 \\
& $(0.085)$ & $(0.071)$ \\
Log land & $-0.381^{* * *}$ & 0.163 \\
& $(0.101)$ & $(0.205)$ \\
\hline Village Fixed Effects & Yes & Yes \\
Mean of X's & No & Yes \\
R-squared & 0.16 & 0.29 \\
Obs. & 505 & 505 \\
Significance levels: & $* 10 \%$ * $10 \% 5 \%$ & $* * * 1 \%$ \\
Notes: The household fixed effect is retrieved for all house- & \\
holds that received food aid more than once &
\end{tabular}




\section{References}

Allingham, Michael G., and Agnar Sandmo (1972) 'Income tax evasion: A theorectical analysis.' Journal of Public Economics 1, 323-338

Bardhan, P., and D. Mookherjee (2005) 'Decentralizing antipoverty program delivery in developing countries.' Journal of Public Economics 89(4), 675-704

Barrett, C.B. (2001) 'Does food aid stabilize food availability?' Economic Development and Cultural Change pp. 335-349

Broussard, Nzinga H. (2011) 'Food aid and adult nutrition in rural Ethiopia.' Agricultural Economics, forthcoming

Caeyers, Bet, and Stefan Dercon (2008) 'Political connections and social networks in targeted transfer programmes: Evidence from rural Ethiopia.' Centre for the Study of African Economies, Working Paper

Clay, D.C., D. Molla, and D. Habtewold (1999) 'Food aid targeting in Ethiopia: A study of who needs it and who gets it.' Food Policy 24(4), 391-409

Conning, J., and M. Kevane (2002) 'Community-based targeting mechanisms for social safety nets: A critical review.' World Development 30(3), 375-394

Dercon, Stefan, and Pramila Krishnan (2003) 'Food aid and informal insurance.' WIDER, Discussion Paper

Dercon, Stefan, Daniel O. Gilligan, John Hoddinott, and Tassew Woldehanna (2009) 'The impact of agricultural extension and roads on poverty and consumption growth in fifteen Ethiopian villages.' American Journal of Agricultural Economics 91(4), 1007-1021

Galasso, E., and M. Ravallion (2005) 'Decentralized targeting of an antipoverty program.' Journal of Public Economics 89(4), 705-727

Gilligan, Daniel O., and John Hoddinott (2007) 'Is there persistence in the impact of emergency food aid? Evidence on consumption, food security, and assets in rural Ethiopia.' American Journal of Agricultural Economics 89, 225-242

Jayne, T.S., J. Strauss, and T. Yamano Daniel (2001) 'Giving to the poor? Targeting of food aid in rural Ethiopia.' World Development 29(5), 887-910 
Jayne, T.S., J. Strauss, T. Yamano, and D. Molla (2002) 'Targeting of food aid in rural Ethiopia: Chronic need or inertia?' Journal of Development Economics 68(2), 247-288

MOFED (2008) The Dynamics of Growth and Poverty (Ministry of Finance and Economic Development, Government of Ethiopia)

Shapouri, S., and M. Missiaen (1990) 'Food aid: Motivation and allocation criteria.' Foreign Agricultural Economic Report

Sharp, K. (1997) 'Targeting food aid in Ethiopia.' Consultancy report for Save the Children Fund (UK). Addis Ababa: SCF-UK

- (1998) Between Relief and Develpoment: Targeting Food Aid for Disaster Prevention in Ethiopia (Overseas Development Institute)

TGE (1993) Directives for disaster prevention and management (Addis Ababa)

Zahariadis, N., R. Travis, and J.B. Ward (2000) 'US food aid to Sub-Saharan Africa: Politics or philanthropy? (l'aide alimentaire américaine à l'afrique subsaharienne: politique ou philanthropie?).' Social Science Quarterly 81(2), 663-676 